\title{
How sports clubs include children and adolescents with disabilities in their activities. A systematic search of peer-reviewed articles
}

\author{
Susanna Geidne ${ }^{1} \cdot$ Kajsa Jerlinder ${ }^{2}$
}

\begin{abstract}
Y oung people with disabilities participate in sports to a lesser extent than other adolescents. That physical activity has positive effects on young people are understood. Sports clubs are identified as potential environments for physical activity. The reasons why young people with disabilities participate to a lower extent in organized sport is complex and barriers can be deriving from many different levels. However, barriers have been studied more than what can facilitate participation in organized sport. Therefor the aim of this study is to increase the understanding of how sports clubs include children and adolescents with disabilities in their activities. The results of this systematic search are presented using the three research questions: What are the characteristics of the sports clubs that include young people with disabilities?; How are the young people with disabilities included in sports clubs' activities?; and finally Why are young people with disabilities included in the sports activities?. A vision must be to go from adapting physical activity for disabled persons to adapting physical activity for all people, because the diversity of people's reasons for doing sports, their differing backgrounds and their uniqueness all demand it. This will result in more people doing sports for longer in life.
\end{abstract}

Keywords: sport-for-all, adapted physical activity, youth, sports club

\footnotetext{
${ }^{1}$ PhD Public Health, Faculty of Medicine and Health, School of Health Sciences, Örebro University, Sweden

${ }^{2} \mathrm{PhD}$ Disability Research, Faculty of Health and Occupational Studies, University of Gävle, Sweden 
How sports clubs include children and adolescents with disabilities in their activities

\section{Introduction}

Positive effects of physical activity on children and adolescents include reduced risk of diabetes, overweight and obesity, anxiety, and depression (EU, 2007; Warburton et al., 2006; World Health Organization, 2010). The benefits, of course, are also great for young people with disabilities (Johnson, 2009; Moran and Block, 2010; Rintala et al., 2011; Shapiro and Martin, 2010; Shields et al., 2012). One of the most important tasks of public health is to find ways to increase physical activity among children and youth with disabilities, thereby improving their health overall (Rimmer and Rowland, 2008). Participation in organized physical activities can lead to greater participation in other everydaylife contexts (Kissow, 2015). Severe obesity and sedentary leisure-time are more common among young people with disabilities than in the rest of the population (Arnhof, 2008; Rimmer and Rowland, 2008).

Participation in organized sports is an important leisure time activity. It is considered beneficial for society for social, educational, cultural and health reasons (Breuer et al., 2015). Sports clubs have been identified as attractive potential environments for physical activity (World Health Organization, 2010) as well as for promoting social and mental health (Bailey et al., 2009; Eime et al., 2008; Fraser-Thomas and Côte, 2006; Fraser-Thomas et al., 2005; Kokko et al., 2011; Moran and Block, 2010). Sports clubs can also contribute to achieving health equity by promoting inclusion and integration (EU, 2007). Documents and guidelines in different countries emphasize that sports should be available for everyone according to their circumstances (EU, 2007; Swedish Sports Confederation, 2009). Sports clubs can also be viewed as health promoting settings (cf. Geidne et al., 2013; Kokko et al., 2016; Kokko et al., 2013).

Given that having a repertoire of leisure activities is essential for quality of life (Block et al., 2013) and health, it is potentially worrisome that young people with disabilities participate in sports to a lesser extent than other adolescents (Blauwet and Iezzoni, 2014; Bult et al., 2011; Carlon et al., 2013; Swedish Agency for Youth and Society, 2012). Mainstream sports opportunities are lacking for people with disabilities (Bantjes et al., 2015; Nixon, 2007). A large number of studies have identified barriers to participation by children and young people with disabilities in organized sports, including personal, social and environmental barriers, as well as barriers at the policy level (Jones, 2003; Shields et al., 2012). Other barriers may be that not all sports clubs accept children and young people with disabilities; leaders lack adequate training; parents fear that their children will be injured or teased; and availability is limited. There may also be economic barriers to participation (Moran and Block, 2010; Rimmer et al., 2004; Shields et al., 2012). Some research offers recommendations on how to include children 
and young people with disabilities into sports activities. One model that can be used for overcoming the barriers is the so-called empowerment model, which includes training, support and programme design (Block et al., 2013). In the model, training includes training coaches and leaders in an inclusive approach and in how to meet the diverse needs of a mixed group, which has been identified as an important factor in the integration of people with disabilities (Grandisson et al., 2012; Shields et al., 2012). Support can come from different sources and take different forms, such as directly supporting the young people or providing indirect assistance to coaches, as well as providing support on how to organize activities (Block et al., 2013). Support can also concerning adapting equipment and activities to meet the needs of youth with disabilities (Grandisson et al., 2012; Shields et al., 2012), or providing scientific knowledge about integration in sports (Shields et al., 2012). Parental support is also mentioned as important (Perkins et al., 2013; Shields et al., 2012). Finally the empowerment model lifts issues such as how recreational programmes can be designed for inclusion and who will run them. This could, for example, be accomplished using different learning models, such as the universal design for learning (UDL) framework (Flores et al., 2013; Sherlock-Shangraw, 2013). Characteristics of the sport can be important; competitive team sports pose greater barriers to participation by young people with disabilities (Jones, 2003; Nixon Ii, 1989) than individual sports, which are easier to adapt to their needs (Grandisson et al., 2012). Constructing an effective network of various actors around the children and young people is recommended (Aujla and Redding, 2013; Dieringer and Judge, 2015). Attitudes in the population in general can also be barriers or a facilitators (Grandisson et al., 2012). Barriers to participation have also been studied more than what can facilitate participation in organized sports (Shields et al., 2012). An overview of inclusion in physical education curricula has found many positive outcomes of inclusion for both students with and without disabilities (Block and Obrusnikova, 2007). A similar overview of inclusion in organized sports of children and adolescents with disabilities is lacking.

The aim of this systematic search is therefore to increase the understanding of how sports clubs include children and adolescents with disabilities in their activities. Specific research questions are: (1) What characterizes sports clubs that include children and young people with disabilities in their activities? (2) How are children and youth with disabilities included? (3) Why do these sports clubs include children and youth with disabilities in their activities? 
How sports clubs include children and adolescents with disabilities in their activities

\section{Method}

\section{Search strategy}

A search was conducted of the following electronic databases to identify relevant studies: Ebscohost (Academic Search Elite, SPORTDiscus, PsycINFO, ERIC, CINAHL Plus with Full Text, MEDLINE, PsycARTICLES); Web of science; Proquest (Social Services Abstracts and Sociological Abstracts); and PubMed. A search strategy was developed for each database centred around four main concepts and their synonyms: disability or impairment; children and young people; sports clubs, sports or organized sports; and finally inclusion. The search included peer-review studies in English between 1 January 1985 and 31 August 2014. Moreover, relevant titles from the reference lists were scanned and authors were contacted. An extended search of the key-words "unified sports", "extra-curricular", and "out-of-school time" was later conducted. However, it did not generate more potential papers to include in this review.

\section{Inclusion and exclusion criteria}

An important consideration in this context is that children's and young people's sports are organized in different ways in different parts of the world (Breuer et al., 2015; De Martelaer and Theeboom, 2006). Voluntary organized sports can be arranged by municipalities or non-governmental organizations (NGOs), as well as by schools as extra-curricular activities after school hours. Moreover, sports for disabled young people can be categorized into three different types (Block et al., 2013): specialized programmes, for example the Special Olympics (offered solely for individuals with disabilities); reverse-inclusion or integration programmes, designed for individuals with disabilities, but also including participants without disabilities, for example wheelchair basketball; and finally inclusion programmes, which are designed for everyone but can be modified when necessary to meet the needs of persons with disabilities.

For the systematic search, the first inclusion criterion was therefore that papers should concern some form of organized sports, defined in this review as voluntary, organized athletic activity for young people. We excluded papers concerning specialized programmes as well as reverse integration/inclusion. The second criterion was that papers should concern children and/or young people with some sort of disability/impairment. The third criterion was that papers should describe how the children and young people were included in the sport activity. A further criteria, that the activity should be regular and ongoing, was abandoned because it eliminated too many studies; hence we have also included specific and temporary interventions that meet the above criteria. 


\section{Data extraction and analysis}

The results of this systematic reviews will be presented using the three research questions: What? (What are the characteristics of the sports clubs that include young people and children with disabilities?); How? (How are the children and young people with disabilities included in sports clubs' activities?); and finally Why? (Why are children with disabilities included in the sports activities?). For the first research question, a form was developed to extract descriptive data including country, type of sport, target group (age, gender), type of disability, recruiting strategies, type of activity (intervention or every day, length of activity) and stakeholders (e.g. parents, physiotherapist etc.). For the second research question, The empowerment model (Block et al., 2013) was used as a model for performing a deductive analysis, and the activities were organized under the categories training, support and programme design. The third research question was answered by searching for reasons for, arguments in favour of, or aims of the activities described in the included papers.

All articles from the initial search were read (title, abstract or full text; see Figure 1) by both authors separately, and decisions on inclusion were made together. Data extraction was performed by the two authors.

\section{Results}

The first search generated 775 titles; many were eliminated on the basis of titles and abstracts alone. Almost half of the papers concerned the school subject Physical Education, while around a third referred to specific medical or physiological aspects of disability in relation to either sports or to different measurement scales of physical activity and attitudes towards inclusion of disabled young people.

Around a quarter of the titles were duplicates (found in more than one the database) and some were in other languages than English (Figure 1). Ultimately, 15 articles were included in the review. 
How sports clubs include children and adolescents with disabilities in their activities

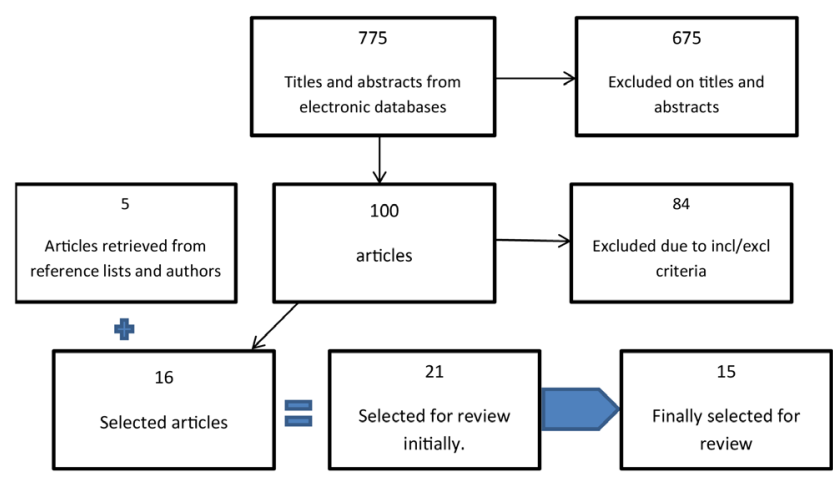

Figure 1. Study selection process

Eleven of the included articles are from the last five years, two from the early 21 st century, and two are more than 20 years old. There are two groups of articles; the first group contains articles that originate from the USA/UK, and the second group concerns articles about a sports programme called Unified Sports originating from different countries.

What are the characteristics of the sports clubs that include children and young people with disabilities?

The sports clubs in the included articles are clubs with a team sport agenda, whose participants have intellectual disability (ID), and where the activity is not a part of the regular programme in the sports clubs, but instead is a specific special activity (intervention) (Table 1). 
Sport Science Review, vol. XXV, No. 1-2, May 2016

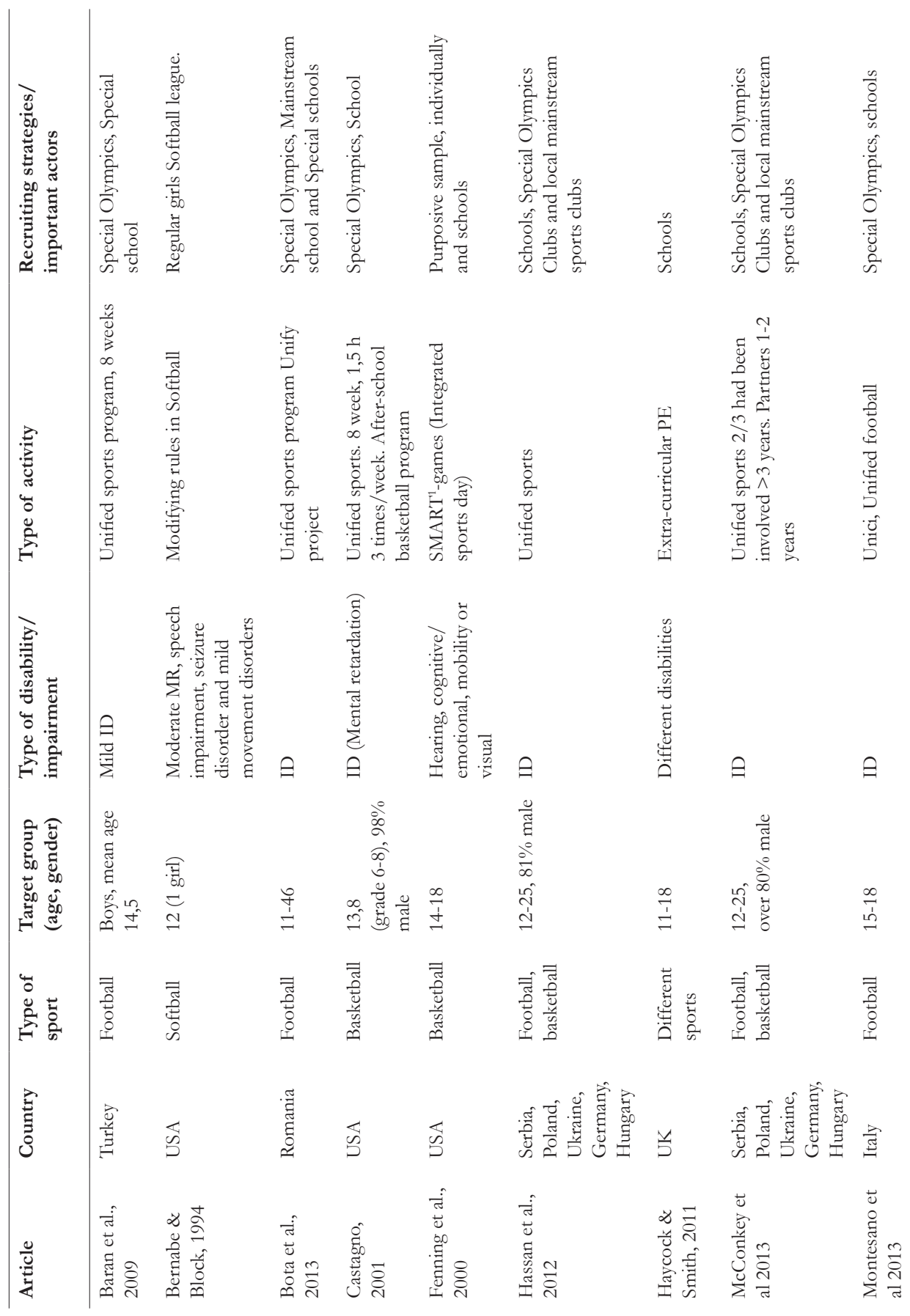


How sports clubs include children and adolescents with disabilities in their activities
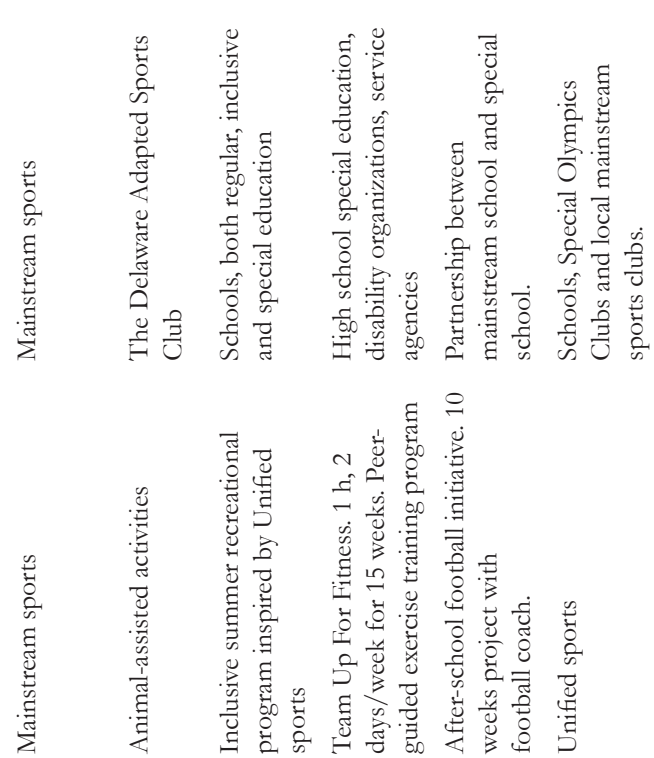

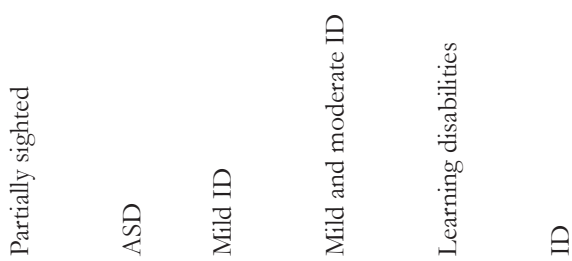

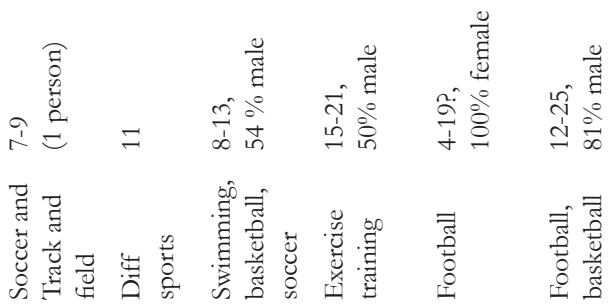

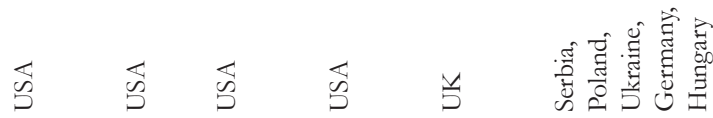

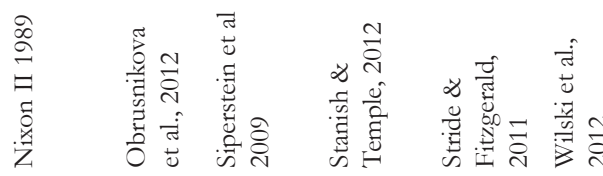

Table 1: Summary of included articles 
The primary recruiting strategy that was documented is recruiting through the schools, as opposed to recruiting through already existing sports activities or health care services. The articles mainly study special activities, or interventions: Few of the reviewed articles concern regular ongoing activities; most of the reviewed articles describe 8-, 10-, or 15-week programmes, summer programmes, or even one-day programmes. Only three articles describe regular ongoing activities. Moreover, sometimes the activities described were solely carried out for research purposes.

Unified Sports is a worldwide Special Olympics programme with half a million participants. The programme promotes social inclusion and sporting skills. In it, people with and without ID train and compete together on the same team. Similar numbers of athletes with and without ID participate. The programme is implemented through Special Olympics clubs, local sports clubs and schools (Special Olympics, http://www.specialolympics.org/unified-sports. aspx).

\section{How are the children and young people with disabilities included?}

Eight of the reviewed articles (Baran et al., 2009; Bota et al., 2014; Castagno, 2001; Hassan et al., 2012; McConkey et al., 2013; Montesano et al., 2013; Siperstein et al., 2009; Wilski et al., 2012) describe a Unified Sports (US) activity or an activity inspired by US. Unified Sports is a specific intervention to promote inclusion of children with and without ID in sports, and to help athletes with ID to take part in mainstream sports in their community. Members with ID (called athletes) and team members without ID (called partners) train and compete side by side. The programme includes a variety of indoor and outdoor sporting events from which to choose. The programme consists not only of activities, but also of a contextual context for the activities, in which stakeholders etc. participate. For each of the chosen activities, participants have to train together for at least 8 weeks, before they can begin competing against other teams.

The other seven articles concern different initiatives to include children and young people in mainstream sports. Two articles concerned modifying rules or adapting activities in relation to a single participating child (Bernabe and Block, 1994; Nixon Ii, 1989). Two analyse how to organize extra-curricular or after-school activities for all students (Haycock and Smith, 2011; Stride and Fitzgerald, 2011) and three report on specific programmes or events (Fenning et al., 2000; Obrusnikova et al., 2012; Stanish and Temple, 2012). Following the empowerment model, the articles can be analysed according to the three subthemes: training, support and programme design (Block et al., 2013). 
How sports clubs include children and adolescents with disabilities in their activities

\section{Training}

Within the sub-theme of training, aspects of training coaches and other participants within the sport clubs were highlighted. How well the coaches are prepared to meet the needs of participants with diverse abilities was discussed. Attitudes towards including participants with disabilities are mentioned as an important factor to acknowledge (Rimmer et al., 2004). General awareness of adaptations towards a more inclusive activity is also discussed. Nixon II (1989) discusses "appropriate and genuine integration", which occurs when actual levels of the impact of both abilities and disabilities is identified and equally accepted. He emphasizes the importance of raising awareness about the aim of the sports activity (competitive or recreational) and the amount of adaption to disability. In the specific special programme of Unified Sports settings, from which eight of the articles originate, coaches have a unique position of role model, both among people involved in the programme and in the surrounding community (Hassan et al., 2012). Coaches selected for this programme have to have previous experience of training participants with disabilities (Hassan et al., 2012). Moreover, not only coaches received training; Stanish and Temple (2012) mention that peer partners also were trained $(2 \times 90 \mathrm{~min})$, but their relationship with disabled training partners was intended to be equal and reciprocal. In the programme described by Obrusnikova and colleagues (2012), therapy dogs used within the programme were specially trained.

\section{Support}

Findings relating to the subtheme of support can be identified within the included articles. Support can either be provided directly to individuals that practise the sport, or benefit them indirectly by going to the organization or coaches. Examples of direct support to participants are the "workout buddy" approach (Stanish and Temple, 2012) and what is described in Bernabe and Block (1994) as maximizing natural support (for example, team members backing each other up during play). Indirect support often comes from parents, for example who serve as assistant coaches (Nixon Ii, 1989). Non-human support, in the form of therapy dogs, is also used to promote physical activity (Obrusnikova and colleagues (2012). In Haycock and Smith (2011), a lack of support is described as resulting from a lack of resources to offer extra-curricular activities and to adapt them to be inclusive and meet the needs of learners with diverse abilities.

\section{Programme design}

The activities for including young people with disabilities exhibited a wide variety of designs, as described in the articles. These designs ranged from 
modifying and adapting a regular activity to identifying characteristics that are successful with all types of participants and designing specific interventions/ programmes. Both Bernabe and Block (1994) and Nixon II (1989) describe a single child's experiences of mainstream sports. In Bernabe and Block (1994) the rules were modified for the specific benefit of a disabled girl in an otherwise mainstream setting, to give her the same opportunity for success without drastically changing the integrity of the game or calling undue attention to her. In Fenning and colleagues (2000), separate divisions with their own rules and specific modifications were created to accommodate the different types of disabilities. A coach in Stride and Fitzgerald (2011) was told to make use of his professional teaching skills by adapting activities while they were underway. Haycock and Smith (2011) conclude that participation is easier when activities are more individualized and recreational, and place less emphasis on success, competition and excellence. Siperstein and colleagues (2009) highlight that it is beneficial for sports activities to be cooperatively structured and to have a recreational, non-competitive focus, so that all children can participate and contribute. Some of the above articles describe mainstream sports settings (Bernabe and Block, 1994; Haycock and Smith, 2011; Nixon Ii, 1989; Stride and Fitzgerald, 2011). However the rest concern specific interventions or programmes, including all eight of the articles about US interventions. Stanish and Temple (2012), for example, study a peer-guided exercise training programme. In addition to the therapy dogs, Obrusnikova and colleagues (2012) include design components like cooperative, competitive and individualistic learning situations.

\section{Why are they included?}

In the included articles, we find three different overall reasons why children and young people with disabilities are included in sports activities. The first is to promote participation by young people with disabilities in mainstream sports. Here we find the unified sports programme with the aim of helping athletes with ID make the transition to mainstream sports (cf. Baran et al., 2009; Siperstein et al., 2009) also describe the aim of their summer recreational programme, inspired by unified sports, as being to use sports as a platform for cooperatively structured activities where all children can participate and contribute equally. Both Stride and Fitzgerald (2011) and Haycock and Smith (2011), in papers from the UK, describe extra-curricular physical education (ECPE). ECPE programmes are not legally required to include pupils with disabilities, however they are expected to work to enhance the involvement of all pupils (Haycock and Smith, 2011). Stride and Fitzgerald (2011), on the other hand, describe a specific intervention conducted as a collaboration between the UK Football Association and the schools, with the aim of promoting participation by disabled girls. Two of the papers concern single case studies (Bernabe and Block, 1994; Nixon Ii, 1989). However Bernabe and Block (1994) describe that the girl in their case 
How sports clubs include children and adolescents with disabilities in their activities

study wants to participate in mainstream sports, both because of her interest in softball and because her friends at school participate.

The second overall aim, found in two specific interventions, is to promote physical activity among disabled adolescents. Stanish and Temple (2012) describe the aim of their exercise training programme as to increase physical fitness among adolescents with ID. Obrusnikova and colleagues (2012) used therapy dogs to promote physical activity among children with autism spectrum disorder.

The third overall aim that can be seen is to promote contact between adolescents with and without disabilities. Fenning and colleagues (2000) describe the aim of the intervention as "promoting sportsmanship behavior and developing understanding of differences among adolescents with and without disabilities".

\section{Discussion}

\section{Main findings}

The characteristics (what) of the sports clubs showed in the reviewed articles are that they have activities with a team sport agenda; that they have participants with ID, preferably recruited through schools; and that the activity is not a part of the regular ongoing activities in the sports clubs but instead is a special time-limited activity (an intervention or a programme).

Factors that need to be addressed concerning how to include children and young people in mainstream sports can be grouped in the categories training, support and programme design. Recommendations on how to implement inclusive sports activities can be summed up in the importance of having coaches who are adequately trained and, equally importantly, are motivated to promote inclusion. Coaches also need both direct and indirect support, for example personnel resources, like parents or peer-partners who can serve as assistant coaches. Inclusive sports programmes can also be diversely designed, depending on the situation, type of activity or type of disability. For example, a regular activity can be modified and adapted, and characteristics can be identified that suit different participants.

Three main reasons were identified why children and adolescents are included in sports clubs. These were to promote the participation of youth with disabilities in mainstream sports, physical activity, or contact between children with and without disabilities. 


\section{Result discussion}

The most important result, however, is that there are very few peerreviewed studies that describe how children and young people with disabilities are included in sports clubs' regular, ongoing activities. Possible reasons for this are that there are few such activities going on in regular sports clubs, that we were unable to find many existing relevant publications, or that there is low interest in documenting and researching those activities. We believe that the last reason is the most probable. Sports clubs' activities occur in local contexts, and when special situations arise the clubs find various ways to solve them. As a result, one might be able to find grey literature about this subject, but much of the good (or not so good) practices that sports clubs carry out in their everyday work may be undocumented and may never have been scientifically evaluated. Haycock and Smith (2011) also emphasize the lack of research into ways that students with special needs have been incorporated into ECPE.

\section{Type of activity}

In the few articles found, the most common type of activity described was team sports, despite the fact that, according to studies (Bernabe and Block, 1994; Haycock and Smith, 2011; Nixon Ii, 1989), inclusion is easier with individual sports. A non-competitive focus is also to be preferred when trying to include a diversity of participants (Bernabe and Block, 1994; Haycock and Smith, 2011; Nixon Ii, 1989; Siperstein et al., 2009). Haycock and Smith (2011) concluded that the activities that were preferred by disabled young people were also preferred by many other pupils without disabilities.

The conclusion that we draw from this is that young people have different needs and aims in doing sports, which makes it important for sports programmes to adapt not just to young people with disabilities, but to everyone. The needs and aims of people doing sports can also change among young people of different ages. However several authors (Bernabe and Block, 1994; Nixon Ii, 1989; Siperstein et al., 2009) conclude that it is easier to conduct inclusive sports for younger children, when the overall differences in skill level are smaller.

Actually all people have different prerequisites for doing sports, but that does not mean that not everyone can do sports. Some barriers are fixed, for example a person's running ability (Shields et al., 2012). However sports should focus on what people can do, not what they cannot do. Children without disabilities also have a variety of learning needs (Flores et al., 2013) and different motives for participating in sports (Shields et al., 2012). All children and young 
people are different and should be given the opportunity to be physically active and participate in a sports clubs in their own way. That means that sports have to be adapted to the participants, not the other way around.

\section{The aim of doing sports, the aim of sports clubs - same or different?}

The aims and activities of sports clubs and organizations around the world are probably as diverse as the number of clubs. There could be a conflict between results-oriented, competitive values and healthy, sports-for-all, democratic values (Peterson, 2008; Skille, 2010; Stenling and Fahlén, 2009). The Swedish sports movement is described by (Fahlén, 2015) as combining professional sports with the popular mass movement tradition in clubs and organizations that arrange various activities along a continuum from popular and amateur to elite and professional. A goal of sports clubs can be to attract more participants, which may be part of a marketing strategy, for example when schools try to attract students by having successful sports teams (Haycock and Smith, 2011). However many of the young people name fun as a reason for participating in sports (Skille and Østerås, 2011). Nixon II (1989) concludes that the purpose of sports activities should be related to the interests of the people they are meant to serve. The question then becomes: Should all sports clubs have the same aim and be able to serve everyone, or should the sports clubs within, for example, a region together be able to cover all people's aims and needs? In that case, who will be responsible for ensuring that society's sports clubs cover everyone's needs and aims?

\section{Who runs sports clubs for children and young people with disabilities?}

In Sweden and some other countries, sports clubs are run by NGOs, often with volunteer coaches. Block and colleagues (2013) emphasize that inclusion programmes often are run by schools or are community-based, however in Sweden all sports clubs that receive public financial support are obliged to adopt an inclusive approach in all youth activities.

The primary recruiting strategy found in this study was to recruit through the schools, not for example through already existing sports activities or health care services. Many actors need to be involved if integration in sports is to work (Grandisson et al., 2012). It is important that the clubs cooperate with other settings, such as schools, local communities and the health sector, and also that other actors in the community see sports clubs as possible partners in developing and strengthening the community's health-promotion work 
(Geidne et al., 2013). Collaboration with the YMCA is mentioned as a model that could be replicated in other countries (Stanish and Temple, 2012). It is not reasonable to assume that all sports clubs regardless of size can provide activities for everyone. Information dissemination to young people with and without disabilities on where to find sports activities must also be developed. Who is responsible in different countries for informing young people or their parents about sports clubs with activities that suit their needs?

\section{Inclusion or integration}

Is inclusion of children and young people with disabilities into sports clubs always the best option, or are there other solutions (Jerlinder, 2010)? The system of segregated sports clubs, i.e. having distinct sports organizations for people with disabilities, may have led to broader segregation (Stride and Fitzgerald, 2011). Hassan and colleagues (2012) conclude that positive integration of people with ID will lead to actual inclusion. However, Haycock and Smith (2011) conclude that inclusion in ECPE has reduced rather than enhanced opportunities for disabled youth. Nixon II (2007) concludes that providing opportunities to participate in mainstream sports does not have to be the ultimate goal of expanding sports opportunities for people with disabilities. Access to recreational, leisure and sporting activities in both inclusive and disability-specific settings is preferable (Rimmer and Marques, 2012). Stride and Fitzgerald (2011) raise the long-term issue of what happens after the short period of training together in a timelimited intervention. This is an issue to reflect on; it must be possible for sports to be an everyday activity for young people with or without disabilities, not just short-term interventions that receive funding for different reasons. Integration in sports is needed not only for young people with disabilities, but for everyone (Nixon Ii, 1989).

\section{Methodological considerations}

A multidisciplinary literature study like this one faces particular kinds of limitations. The choices of keywords, databases and inclusion/exclusion criteria could have been done differently. We argue that our choices gave us a broader sample from the beginning, so that we would not miss out on relevant articles. However the toughest selection concerned those papers that provided recommendations for how organized sports could include young people with disabilities, but did not provide actual examples of inclusion. Finding how young people actually are included was difficult; sometimes a paper had another purpose but described a situation where youth with disability are included in great detail. This led us to include more articles in the review than we would have done with a more strict approach, which is a strength. Some of the reviewed articles about US do not contain explicit descriptions of how 
sports clubs can include children with disabilities in their ordinary activities. Instead, they evaluate changed attitudes, perceived sportsmanship and learning (Fenning et al., 2000), or overall satisfaction with the programme (Baran et al., 2009). Nevertheless, the steps for creating inclusion are clearly present in the reviewed articles. Block and colleagues (2013) see Unified Sports as a reverse inclusion programme. However we have chosen to include the papers about the programme, because the young people in it train together regularly and the programme is run in both organized sports clubs and mainstream schools.

A strength when it comes to dealing with this multidisciplinary topic is that the authors have expertise in different scientific areas within sports studies, including both quantitative and qualitative methodologies. Despite the efforts made to insure a broad and comprehensive search, it is possible that not all of the relevant studies were found.

Can disabled young people, a very heterogeneous group, be considered as one group? We argue that considering the small number of included articles it would not have been possible to divide up the group in any other way.

We did not perform a structured quality check of the included articles, however something can be said about quality. Some of the papers in this review report on preliminary research and their methodological quality can be questioned. They were nevertheless included because they met the inclusion criteria for this review (peer-reviewed publications in international research journals) and contribute to this somewhat limited field of knowledge. While this review is restricted to peer-reviewed publications, a review that includes grey literature could add more to the subject, because it is within the organizations that these activities occur and where pragmatic solutions are developed.

\section{Conclusion and practical implications}

It is essential to establish a knowledge base on both effective interventions and examples of best practice in everyday activities regarding the target group at hand. If more children and youth with disabilities participate in organized sports several positive health benefits can be achieved.

There is a need to study real examples of how sports clubs can include children and youth with disabilities in their activities. There are many studies about recommendations, barriers and facilitators, but what are sports clubs actually doing? Might it be that the sports clubs know things that work better in practice? There is a need for pilot projects testing different approaches to integrating adolescents with ID (Grandisson et al., 2012). 
There is ongoing work both in Sweden and internationally that emphasizes a life-span approach in sports, but also that sports are for everyone, regardless of ambition level (Kokko et al., 2015; Swedish Sports Confederation, 2015). We must go from adapting physical activity for disabled persons to adapting physical activity for all people, because the diversity of people's reasons for doing sports, their differing backgrounds and their uniqueness all demand it. Such an approach will result in more people doing sports for longer in life, which will benefit everyone, both individually and at the societal level.

\section{References}

Arnhof Y.(2008) Onödighälsa. Hälsoläget förpersonermed funktionsnedsättning. In: Statens Folkhälsoinstitut (ed). Ostersund.

Aujla IJ and Redding E. (2013) Barriers to dance training for young people with disabilities. British Journal of Special Education 40: 80-85.

Bailey R, Armour K and Kirk D. (2009) The educational benefits claimed for physical education and school sport: an academic review. Research Papers in Education 24: 1-28.

Bantjes J, Swartz L, Conchar L, et al. (2015) Developing Programmes to Promote Participation in Sport among Adolescents with Disabilities: Perceptions Expressed by a Group of South African Adolescents with Cerebral Palsy. International Journal of Disability, Development and Education 62: 288-302.

Baran F, Top E, Aktop A, et al. (2009) Evaluation of a Unified football program by Special olympics athletes, partners, parents, and coaches. European Journal of Adapted Physical Activity 2: 34

Bernabe EA and Block ME. (1994) Modifying rules of a regular girls' softball league to facilitate the inclusion of a child with severe disabilities. Journal of the Association for Persons with Severe Handicaps 19: 24-31.

Blauwet CA and Iezzoni LI. (2014) From the Paralympics to public health: increasing physical activity through legislative and policy initiatives. PM \& $\mathrm{R}$ : the journal of injury, function, and rebabilitation 6: S4.

Block ME and Obrusnikova I. (2007) Inclusion in physical education: A review of the literature from 1995-2005. Adapted Physical Activity Quarterly 24: 103-124. 
How sports clubs include children and adolescents with disabilities in their activities

Block ME, Taliaferro A and Moran T. (2013) Physical Activity and Youth with Disabilities: Barriers and Supports. Prevention Researcher 20: 18.

Bota A, Teodorescu S and Serbanoiu S. (2014) Unified Sports - a Social Inclusion Factor in School Communities for Young People with Intellectual Disabilities. 3rd International Congress on Physical Education, Sport and Kinetotherapy (Icpesk. 2013) 117: 21-26.

Breuer C, Hoekman R, Nagel S, et al. (2015) Sport Clubs in Europe: A CrossNational Comparative Perspective. Berlin: Springer.

Bult MK, Verschuren O, Jongmans MJ, et al. (2011) What influences participation in leisure activities of children and youth with physical disabilities? A systematic review. Research in Developmental Disabilities 32: 1521-1529.

Carlon SL, Taylor NF, Dodd KJ, et al. (2013) Differences in habitual physical activity levels of young people with cerebral palsy and their typically developing peers: a systematic review. Disability and Rehabilitation 35: 647-655.

Castagno KS. (2001) Special olympics unified sports: Changes in male athletes during a basketball season. Adapted Physical Activity Quarterly 18: 193-206.

De Martelaer K and Theeboom M. (2006) Physical education and youth sport. The Handbook of Physical Education. Sage Publications.

Dieringer ST and Judge LW. (2015) Inclusion in Extracurricular Sport: A HowTo Guide for Implementation Strategies. 201572.

Eime RM, Payne WR and Harvey JT. (2008) Making sporting clubs healthy and welcoming environments: A strategy to increase participation. Journal of Science and Medicine in Sport 11: 146-154.

EU. (2007) White Paper on Sport. Commisssion of the European communities.

Fahlén J. (2015) Sport Clubs in Sweden. In: Breuer C, Hoekman R, Nagel S, et al. (eds) Sport Clubs in Europe. A cross-National Comparative Perspective. Springer, 343-368.

Fenning P, Parraga M, Bhojwani V, et al. (2000) Evaluation of an integrated disability basketball event for adolescents: Sportsmanship and learning. Adapted Physical Activity Quarterly 17: 237-252. 
Flores MM, Beyer R and Vargas TM. (2013) Making Youth Sports Accesible to All Athletes through Coaching Based on Universal Design for Learning. YouthFirst: The Journal of Youth Sports 7: 19-25.

Fraser-Thomas J and Côte J. (2006) Youth sports: Implementing Findings and Moving Forward with Research. Athletic Insight 8: 12-27.

Fraser-Thomas J, Côté J and Deakin J. (2005) Youth sport programs: an avenue to foster positive youth development. Physical Education and Sport Pedagogy 10: $19-40$.

Geidne S, Quennerstedt M and Eriksson C. (2013) The youth sports club as a health-promoting setting: An integrative review of research. Scandinavian Journal of Public Health 41: 269-283.

Grandisson M, Tétreault S and Freeman AR. (2012) Enabling Integration in Sports for Adolescents with Intellectual Disabilities. Journal of Applied Research in Intellectual Disabilities 25: 217-230.

Hassan D, Dowling S, McConkey R, et al. (2012) The inclusion of people with intellectual disabilities in team sports: lessons from the Youth Unified Sports programme of Special Olympics. Sport in Society 15: 1275-1290.

Haycock D and Smith A. (2011) Still 'more of the same for the more able?' Including young disabled people and pupils with special educational needs in extra-curricular physical education. Sport, Education \& Society 16: 507-526.

Jerlinder K. (2010) Social rättvisa i inkluderande idrottsundervisning för elever med rörelsehinder: en utopi? Studies from The Swedish Institute for Disability Research,. Örebro: Örebro universitet.

Johnson CC. (2009) The Benefits of Physical Activity for Youth With

Developmental Disabilities: A Systematic Review. American Journal of Health Promotion 23: 157-167.

Jones DB. (2003) “Denied from a Lot of Places" Barriers to Participation in Community Recreation Programs Encountered by Children with Disabilities in Maine: Perspectives of Parents. Leisure/Loisir 28: 49-69.

Kissow A-M. (2015) Participation in physical activity and the everyday life of people with physical disabilities: a review of the literature. Scandinavian Journal of Disability Research 17: 144-123. 
How sports clubs include children and adolescents with disabilities in their activities

Kokko S, Donaldson A, Geidne S, et al. (2016) Piecing the puzzle together: Case studies of international research in health promoting sports clubs. Global Health Promotion. In press.

Kokko S, Green LW and Kannas L. (2013) A review of settings-based health promotion with applications to sports clubs. Health promotion international.

Kokko S, Koski P, Oja P, et al. (2015) Sports clubs for health (SCforH) II project - Promoting national implementation of SCforH programs in EU member states. 6th HEPA Europe Conference, . İstanbul, Turkey.

Kokko S, Oja P, Foster C, et al. (2011) Sports Club for Health - Guidelines for health-oriented sports activities in a club setting. Finnish Sport for All Association.

McConkey R, Dowling S, Hassan D, et al. (2013) Promoting social inclusion through Unified Sports for youth with intellectual disabilities: a five-nation study. Journal of Intellectual Disability Research 57: 923-935.

Montesano P, Tafuri D, Esposito A, et al. (2013) Conditional abilities in young Special Olympics athletes who practice unified football. Journal of Physical Education and Sport 13: 504-510.

Moran TE and Block ME. (2010) Barriers to Participation of Children with Disabilities in Youth Sports. TeACHING Exceptional Children Plus 6: 1-13.

Nixon HL, II. (2007) Constructing Diverse Sports Opportunities for People with Disabilities. Journal of Sport and Social Issues 31: 417-433.

Nixon Ii HL. (1989) Integration of Disabled People in Mainstream Sports: Case Study of a Partially Sighted Child. Adapted Physical Activity Quarterly 6: 17-31.

Obrusnikova I, Cavalier AR, Bibik JM, et al. (2012) Integrating Therapy Dog Teams in a Physical Activity Program for Children with Autism Spectrum Disorders. JOPERD: The Journal of Physical Education, Recreation \& Dance: 37-48.

Perkins K, Columna L, Lieberman L, et al. (2013) Parents' perceptions of physical activity for their children with visual impairments. Journal of $V$ isual Impairment and Blindness 107: 131-142.

Peterson T. (2008) Föreningsfostran och tävlingsfostran. En utvärdering av statens stöd till idrotten. In: Swedish Government SOU 2008:59 (ed). Stockholm: Fritzes. 
Rimmer J, Riley B, Wang E, et al. (2004) Physical activity participation among persons with disabilities: Barriers and facilitators. American Journal of Preventive Medicine 26: 419-425.

Rimmer JA and Rowland JL. (2008) Physical activity for youth with disabilities: A critical need in an underserved population. Developmental Neurorebabilitation 11: 141-148.

Rimmer JH and Marques AC. (2012) Physical activity for people with disabilities. The Lancet 380: 193-195.

Rintala P, Välimaa R, Tynjälä J, et al. (2011) Physical activity of children with and without long-term illness or disability. Journal of Physical Activity and Health 8: 1066-1073.

Shapiro DR and Martin JJ. (2010) Athletic identity, affect, and peer relations in youth athletes with physical disabilities. Disability and Health Journal 3: 79-85.

Sherlock-Shangraw R. (2013) Creating Inclusive Youth Sport Environments with the Universal Design for Learning. JOPERD: The Journal of Physical Education, Recreation \& Dance 84: 40-46.

Shields N, Synnot AJ and Barr M. (2012) Perceived barriers and facilitators to physical activity for children with disability: a systematic review. British Journal of Sports Medicine 46: 989-997.

Siperstein GN, Glick GC and Parker RC. (2009) Social Inclusion of Children With Intellectual Disabilities in a Recreational Setting. Intellectual and Developmental Disabilities 47: 97-107.

Skille E and Østerås J. (2011) What does sport mean to you? Fun and other preferences for adolescents' sport participation. Critical Public Health 21: 359372.

Skille EÅ. (2010) Competitiveness and health: The work of sport clubs as seen by sport clubs representatives - a Norwegian case study. International Review for the Sociology of Sport 45: 73-85.

Stanish HI and Temple VA. (2012) Efficacy of a peer-guided exercise programme for adolescents with intellectual disability. J Appl Res Intellect Disabil 25: 319328. 
Stenling C and Fahlén J. (2009) The order of logics in Swedish sport - feeding the hungry beast of result orientation and commercalization European Journal for Sport and Society 6:121-134.

Stride A and Fitzgerald H. (2011) Girls with learning disabilities and 'football on the brain'. Soccer \& Society 12: 457-470.

Swedish Agency for Youth and Society. (2012) Levnadsillkor för unga med funktionsnedsättning. In: Ungdomsstyrelsen (ed) FOKUS12. Stockholm: Ungdomsstyrelsens skrifter.

Swedish Sports Confederation. (2009) Idrotten vill. Stockholm.

Swedish Sports Confederation. (2015) RS Förslag: Strategi för Svensk idrotts framtid. RF-stämman i Helsingborg 29-31 maj 2015.

Warburton DER, Nicol CW and Bredin SSD. (2006) Health benefits of physical activity: The evidence. CMAJ 174: 801-809.

Wilski M, Nadolska A, Dowling S, et al. (2012) Personal development of participants in special olympics unified sports teams. Human Movement 13: 271-279.

World Health Organization. (2010) Global recommendations on physical activity for health. In: World Health Organization (ed). Geneva. 
Susanna GEIDNE, PhD is a researcher in Public Health and a senior lecturer in Sport Science in the School of Health Sciences at Örebro University in Sweden. Geidne's research interest lie in the area of health promoting settings, health promoting sports clubs, schools and NGO's as well as alcohol and drug prevention.

\section{Corresponding address:}

Dr. Susanna Geidne

Faculty of Medicine and Health

School of Health Sciences

Örebro University

70182 Örebro

Sweden

Email: susanna.geidne@oru.se

Kajsa JERLINDER, PhD is a lecturer in Sport Science in Faculty of Health and Occupational Studies at the University of Gävle in Sweden. Jerlinder's research interests lie in the areas of adapted physical activity, inclusion, participation, social justice, special needs education. 
